\title{
Level of Bruising and DFD Carcasses from Bulls of Arsi, Boran and Harar Cattle Breeds in Ethiopia
}

\author{
Addis Fikrie Birhanu1 ${ }^{*}$, Yesihak Yusuf Mummed², Mohammad Yousuf Kurtu² \\ ${ }^{1}$ Beef Cattle, Camel and Small Animals Meat Product Research and Processing Industry Development Directorate, Ethiopian Meat \\ and Dairy Industry Development Institute/EMDIDI, Bishoftu, Ethiopia \\ ${ }^{2}$ School of Animal and Range Science, College of Agriculture and Environmental Science, Haramaya University, Dire Dawa, Ethiopia \\ Email: *addsfkr@gmail.com
}

How to cite this paper: Birhanu, A.F., Mummed, Y.Y. and Kurtu, M.Y. (2020) Level of Bruising and DFD Carcasses from Bulls of Arsi, Boran and Harar Cattle Breeds in Ethiopia. Open Journal of Animal Sciences, 10, 203-218.

https://doi.org/10.4236/ojas.2020.101011

Received: November 21, 2019

Accepted: January 19, 2020

Published: January 22, 2020

Copyright $\odot 2020$ by author(s) and Scientific Research Publishing Inc. This work is licensed under the Creative Commons Attribution International License (CC BY 4.0).

http://creativecommons.org/licenses/by/4.0/

\begin{abstract}
The objective of the study was to determine the level of Bruising and Dark Firm Dry on Arsi, Boran and Harar cattle breeds in Ethiopia. A total of 39 beef bulls from three different breeds (14 Boran, 14 Harar, and 11 Arsi cattle breeds) were used in this study. Based on the present finding, from 39 slaughtered beef bulls $66.7 \%$ was bruised and $30.77 \%$ produced DFD meat. Harar breed had the highest (39.1\%) overall level of bruising while Boran and Arsi had the lowest level. However, Harar breed had the lowest level of DFD (14.29\%). Age groups 3 - 6 and 6 - 9 years had the highest level of a bruise (29.70\% and $28.10 \%$, respectively) compared to age groups $2-3$ years. The mean number of bruises per carcass was $1.96 \pm 0.25$ while the bruise score per carcass was $3.58 \pm 0.68$. A linear bruise was the most observed (33.33\%) shape of a bruise. It was concluded that the level of bruising and DFD was higher compared to some other abattoir studies in other countries which indicated the possible presence of poor handling practice of cattle from farm to abattoir gates. To minimize the incidence of DFD and bruising, it was recommended that proper handling of cattle during loading, transport, unloading, at lairriage and during slaughter need to be practiced.
\end{abstract}

\section{Keywords}

Bruise, Dark Firm Dry, Bulls and Carcass

\section{Introduction}

Ethiopia has 59.5 million heads of cattle, 30.70 million heads of sheep, 30.20 mil- 
lion heads of goats, 56.53 millions of poultry and 1.21 million heads of a camel [1]. It is central to the Ethiopian economy contributing about $45 \%$ to the agricultural GDP, supporting the livelihoods of $70 \%$ of the population, $18.7 \%$ to the national GDP and 16\% - 19\% to the total foreign exchange earning of the country [2].

One of the major challenges facing the domestic consumption and meat export abattoirs has been that quality of livestock supply which is influenced by lack of proper pre-slaughter handling and transportation of animals [3]. Pre-slaughter stress would end up producing bruised and dark firm dry meats which affect animal welfare and meat quality [4]. Bruises can occur at any point of the meat chain, due to inappropriate handling of the animal on the farm or at livestock market, during loading, through road transport, unloading at the slaughterhouse, penning and even during stunning procedures [5].

Bruised meat is not acceptable to the consumers and ends up in the wastage of the product. It is less likely to be used for processing as it yields poor product. It decomposes and spoils rapidly as the bloody meat is an ideal medium for growth of contaminating bacteria. For the above reasons, it must be trimmed and condemned at meat inspection. Furthermore, if secondary bacterial infection occurs on the bruised muscle, abscess is formed causing the entire carcass to be condemned. DFD meat also possibly faces consumer rejection due to its dark red colour, toughness, undesirable flavor and poor shelf life. It is less likely to be used for further processing as it is prone to spoilage as a result of higher $\mathrm{pH}$ and an increased water-holding ability. Bruising and DFD lower the quality of carcass or impose meat producer to discount a value of cuts or carcass. Because of these, they are serious problems for the fresh meat market and cause large economic losses to suppliers, meat industry and the country [6] [7]. Bruising and DFD had received more attention from researcher and the beef industry due to such substantial economic burden and possible animal welfare implications [8].

There was no documented information on the level of bruising of carcasses and DFD meat in Ethiopia. Determining levels of bruising and DFD may help in implementing procedures that enhance good welfare of animals and meat quality in the country. Therefore, the object of this study was to determine the level of bruising of carcass and DFD meat from Arsi, Boran and Harar Cattle breeds under different age groups in Ethiopia.

\section{Materials and Methods}

\subsection{Description of Study Sites}

The study was conducted from October 2017 to May 2018 on cattle purchased from different places and slaughtered at Elfora Bishoftu export abattoirs which found at bishoftu town. Arsi and Harar breeds purchased from cattle market at West Arsi (kofale) and West Hararghe (Chiro) respectively. However, Boran breed from Dida tuyera ranch, Borena Zones (Yabello). West Arsi is located at $7^{\circ} 19^{\prime}$ to $7^{\circ} 40^{\prime} \mathrm{N}$ and $38^{\circ} 30^{\prime}$ to $38^{\circ} 35^{\prime} \mathrm{E}$ with an elevation of 2695 meters above sea 
level. West Hararghe zone is located at altitude between 970 and 1410 meter above sea level. The annual rainfall ranges from $650 \mathrm{~mm}-950 \mathrm{~mm}$ and mean temperature range between $17.5^{\circ} \mathrm{C}-27^{\circ} \mathrm{C}$. Borana zone located at $3^{\circ} 26^{\prime}-6^{\circ} 32^{\prime} \mathrm{N}$ latitude and $36^{\circ} 43^{\prime}-40^{\circ} 46^{\prime} \mathrm{E}$ longitudes with altitude below $1500 \mathrm{~m}$ above mean sea level. The area characterized by semi-arid lowland with an average rainfall ranging from 300 to $600 \mathrm{~mm}$ and average daily temperature from $19^{\circ} \mathrm{C}$ to $26^{\circ} \mathrm{C}$. Mixed crop-livestock production system is practiced in the Arsi and Hararghe regions in which grazing and crop residue feeding were common. Pastoral range livestock production system is practiced in Borena zone in which cattle mostly depend on grazing natural pasture which is dominated by perennial grasses (Cenchrus, Pennisetum, and Chrysopogon species).

\subsection{Animal Management}

A total of 39 bulls consisting of three breeds (Boran, Harar and Arsi) were used for the study. The bulls were grouped into three age groups as group I contained cattle with 2 - 3 years of age, group II contained cattle with 3 - 6 years of ages and group III contained cattle with 6 - 9 years of ages. Ages of cattle were determined by dentition according to [9]. Bulls from Boran breed were directly loaded from ranch while a bull from Arsi and Harar breeds directly from the market. Bulls of each breed were transported by FSR trucks to export abattoir for the same distance. On arrival at the abattoirs, unloading activities were monitored and cattle were provided with feed and water ad-libtium according to abattoir animal handling guideline. Cattle were stayed in lariage for 18 hours without provision of feed. Later they were stunned and slaughtered using standard operating procedures of the abattoir.

\subsection{Bruise Measurement}

Carcass bruise score assessment was done for 39 beef carcasses using a method based on the Australian Carcass Bruise Score System [10]. After dressing, the carcasses were examined for the numbers of bruises per carcass and bruises by anatomical site (butt, rump-loin, ribs, forequarter, back, pin and hip. The size, colour and shape of every bruise were recorded. The size of each bruise was measured on the basis of its diameter as: little $(<2 \mathrm{~cm})$, slight $(2-8 \mathrm{~cm})$, medium $(8-16$ $\mathrm{cm})$ or heavy $(>16 \mathrm{~cm})$ by using a ruler. When a bruise was not circular, the diameter was measured as the longest length of the lesion. To assist with the visual appraisal of the bruises, a hard paper indicating circular areas of 2,8 and $16 \mathrm{~cm}$ was used. Bruise scores were calculated for each bruised carcass by multiplying the number of bruises in each size class (little, slight, medium or heavy) by a weighing factor (little 0 , slight 1 , medium 3 and heavy 5) and adding these values. Little bruises $(<2 \mathrm{~cm})$ were not considered. These bruise scores then divided by the number of bruised carcass to give a mean bruise score per carcass. Level of bruise by size category was counted for different breed and age categories from the total bruise. Bruise age was estimated using the method of [11] as described in Table 1. 
Table 1. Colour observations used to estimate the age of bruises.

\begin{tabular}{cc}
\hline Observable colour of bruise & Estimated age of the bruise (hours) \\
\hline Red and hemorrhagic (bright red) & $0-10$ hours \\
Dark-red colour & $11-24$ hours \\
Watery consistency & $25-38$ hours \\
Rusty orange colours, soapy to touch, clear yellow mucus. & $>72$ hours (at least 3 days old) \\
Gracey et al. (1999). & \\
\hline
\end{tabular}

\subsection{Meat pH Measurement for Detection of Dark Firm Dry}

The $\mathrm{pH}$ measurement done according to procedure described by [12]. The $\mathrm{pH}$ and temperature measured using Portable HANNA pH or temperature meter (model number-HI99163) in the Muscularis longisimus thoracis et. Lumborum (LTL) at the depth of $3-4 \mathrm{~cm}$ while carcasses were at hanging position and by removing samples from the loin region. The $\mathrm{pH}$ meter was calibrated before taking measurement and in every measurement using $\mathrm{pH} 4$ and $\mathrm{pH} 7$ standard buffer solutions. During each $\mathrm{pH}$ measurement series the immersed sensor tip or electrode was rinsed immediately and thoroughly with distilled water and dried carefully with a clean paper towel. After measurement the carcasses with $\mathrm{pH}_{24}$ hours lower than 5.8 were classified as normal quality and carcasses with $\mathrm{pH}_{24}$ hours value greater than or equal to 5.8 as DFD meat according to previous recommendation [12] [13].

\subsection{Determination of Meat Colour}

The color of meat was measured in triplicate 24 hours after slaughter in the Muscularis longisimus thoracis et. Lumborum (LTL), $3 \mathrm{~cm}$ thick sample removed from the area between the 12th and 13th ribs from right side carcass at free fat area. Measurements were made after 30-min exposure to air (bloom time) on the different locations of the surface of the muscle using a Mini Scan EZ machine (model number-4500L) with a $20 \mathrm{~mm}$ diameter measurements area and illuminant D65-day light, $10^{\circ}$ standard observer. The machine was standardized before taking measurements using the black and white colour standard samples provided for this purpose. Three readings were taken on each sample by rotating the Colour Guide $90^{\circ}$ between measurements so as to obtain the average value for the colour and meat colour was expressed using the CIELAB color space $\left(\mathrm{L}^{*}=\right.$ lightness, $\mathrm{a}^{*}=$ redness, and $\mathrm{b}^{\star}=$ yellowness) according to the CIE system [14] [15].

\subsection{Measurement of Subcutaneous Fat Thickness}

The thickness of subcutaneous fat (TSF) measured by a caliper averaging three points between the $12^{\text {th }}$ and $13^{\text {th }}$ ribs of longissimus muscle and expressed in inch.

\subsection{Statistical Analysis}

The data was analyzed by Statistical Analysis System 9.3 version (SAS, 2011). 
Descriptive statistics were used to determine levels of bruising and DFD. Pearson's chi-square test was done to compare the level of DFD for the breed and age category. General Linear Model procedure (PROC GLIMMIX; SAS, 2011) was used to compare beef quality parameter $(\mathrm{pH}$, temperature and colour) for normal and DFD meat. Significant differences among least square group means were compared using pdiff when $\mathrm{F}$ test was statistically significant $(\mathrm{P}<0.05)$.

The model used was:

$$
Y_{i j}=\mu+\alpha_{i}+\beta_{j}+\varepsilon_{i j}
$$

where,

$Y_{i j}=$ response variable $\left(\mathrm{pH}\right.$, temperature, $\left.\mathrm{WHC}, \mathrm{L}^{*}, \mathrm{a}^{*}, \mathrm{~b}^{*}\right)$.

$N=$ Constant mean common to all observations.

$\alpha_{i}=$ Breed (Harar, Boran, Arsi).

$\beta_{j}=$ Age (group 1, group 2 and group 3).

$E_{i j}=$ random error.

\section{Results and Discussion}

\subsection{Level of Dark Firm Dry Beef}

The level of DFD beef in slaughtered cattle in the present study is shown in Figure 1 . The result of the study showed that from a total of 39 beef cattle slaughtered, 27 bull (69.23\%) had ultimate $\mathrm{pH}$ ( $\mathrm{pH}_{24}$ hours) less than 5.8 (normal meat) and 12 bulls (30.77\%) had ultimate $\mathrm{pH}$ greater than or equal to 5.8 (DFD meat) in longissimus dorsi muscle. The current level of DFD in slaughtered cattle were high compared to level of DFD for cattle slaughtered at South Africa local commercial abattoir which was 7.3\% - 11.8\% [16], 4.53\% for Brazilian commercial crossbred cattle [17], 3.2\% in USA [18], 1.6\% in Canada [19] grain finished cattle in USA which were in the range between $1.5 \%$ and $5 \%$ [20]. The higher proportion of DFD might be associated with the absence of enough glycogen stored by the cattle before slaughter. Most of cattle slaughtered at public abattoirs in Ethiopia had low grade of fat (fat grade 1) based on beef classification system of Ethiopia [21]. Moreover, cattle were exposed to a number of stress which started from farm, transport which was usually trekking, during marketing, lairriage and by methods of slaughter [22] [23]. The present finding alert the need to look for strategies to minimize the incidence of DFD beef produced in Ethiopia.

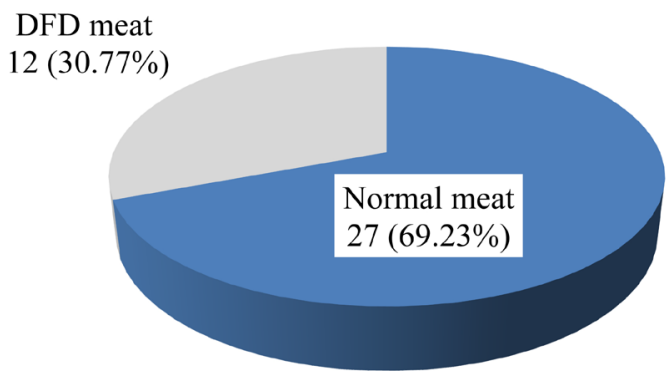

Figure 1. Level of DFD and Normal carcass of slaughtered beef cattle. 


\subsubsection{Level of Dark Firm Dry for Arsi, Boran and Harar Beef Cattle}

The level of DFD and normal carcass were evaluated for Arsi, Boran and Harar beef cattle (Table 2). From a total of each slaughtered cattle, Arsi breed account $54.54 \%$, Boran breed $64.29 \%$ and Harar breed $85.71 \%$ normal carcasses. The highest level of DFD, which account $45.45 \%$ for Arsi breed was statistically not significant $(\mathrm{P}>0.05)$ from intermediate level of DFD (35.71\%) for Boran and the least level of DFD (14.29\%) for Harar breed. The absence of significant difference between breed for DFD can suggest the importance of pre-slaughter handling of animals on DFD than breed of animals. The current finding in line with Sanz et al. (1996) who reported that no differences in occurrence of DFD between Brown Swiss and the Pirenaico breed but disagreement with [24] who found difference in incidence of DFD among Friesian, Brown Swiss and Eastern Anatolian Red (23\%, 34\% and 25\% respectively) beef breed.

\subsubsection{Level of Dark Firm Dry for Beef Cattle Slaughtered at Different Age Groups}

The level of DFD and normal carcass was evaluated for beef cattle slaughtered at different age groups (Table 3). From a total of each age group, 53.85\% that was found at the age of $2-3$ years, $85.71 \%$ at the age of $3-6$ years and $66.67 \%$ at the age of 6 - 9 years old was normal carcasses. The level of DFD among age group was not significantly different $(P>0.05)$. Numerically, the highest level of DFD accounted $46.15 \%$ in the age group $2-3$ years followed by age group 6 - 9 years old (33.33\%) and 3 - 6 years (14.29\%), respectively. This result was in agreement with previous research work done by [25] who reported that no significant difference among young male cattle slaughtered at different ages.

\subsection{Quality Characteristics of Normal and DFD Beef}

Quality characteristics of normal and DFD beef are presented in Table 4 . The mean ultimate $\mathrm{pH}$ of normal and DFD beef were $5.54 \pm 0.07$ and $6.16 \pm 0.04$, respectively. Normal beef was relatively lighter $(\mathrm{P}<0.05)$ than DFD Meat with $\mathrm{L}^{*}$ values of $34.29 \pm 0.59$ and $31.53 \pm 0.83$, respectively. However, difference in terms of pH45 min, Temp24 hours, $\mathrm{a}^{*}$ and $\mathrm{b}^{*}$, for the two meat groups were not significant. The $\mathrm{pH}$ of normal meat drops from initial $\mathrm{pH} 6.16$ to 5.54 after 24 hours of carcass chilling at $0^{\circ} \mathrm{C}-4^{\circ} \mathrm{C}$ while in DFD meat did not drop with significant figure. The possible absence of drop in $\mathrm{pH}$ of DFD beef might be associated with depletion of glycogen due to stress of the animal which finally didn't produce significant acidification due inability to produce enough lactic acid.

Experimental cattle were transported up to 16 hours, at high transit temperature up to $36^{\circ} \mathrm{C}$, exposure to cold and rainy environment alternatively, long hours of deprivation water and feed up to 36 hours. Animals exposed to stress during transport from farm to abattoir. The stress trigger depletion of muscle glycogen which might be mobilized by rapid release of stress enzymes and hormones, this results in glycogen depletion in muscle at slaughter, formation of insufficient amount of lactic acid, and correspondingly, low fall in muscle $\mathrm{pH}$ post 
Table 2. Percentage of normal and DFD carcass for Arsi, Boran and Harar breeds.

\begin{tabular}{cccccc}
\hline Breed & $\mathrm{N}$ & $\begin{array}{c}\text { Normal } \\
\left(\mathrm{pH}_{24}<5.8\right)\end{array}$ & $\begin{array}{c}\mathrm{DFD} \\
\left(\mathrm{pH}_{24} \geq 5.8\right)\end{array}$ & Chi-square & P-value \\
\hline Arsi & 11 & $6(54.54 \%)$ & $5(45.45 \%)$ & & \\
Boran & 14 & $9(64.29 \%)$ & $5(35.71 \%)$ & 3.06 & 0.21 \\
Harar & 14 & $12(85.71 \%)$ & $2(14.29 \%)$ & & \\
Total & 39 & $27(69.23 \%)$ & $12(30.77 \%)$ & & \\
\hline
\end{tabular}

$\mathrm{N}=$ Total number of animals per breed, $\mathrm{pH}_{45}=\mathrm{pH}$ measured at 45 minute, $\mathrm{pH}_{24}=\mathrm{pH}$ measured at 24 hour (ultimate $\mathrm{pH}$ ), DFD = Dark, Firm and Dry.

Table 3. Percentage of normal and DFD carcass for different age groups.

\begin{tabular}{cccccc}
\hline $\begin{array}{c}\text { Age } \\
\text { (years) }\end{array}$ & $\mathrm{N}$ & $\begin{array}{c}\text { Normal } \\
\left(\mathrm{pH}_{24}<5.8\right)\end{array}$ & $\begin{array}{c}\mathrm{DFD} \\
\left(\mathrm{pH}_{24} \geq 5.8\right)\end{array}$ & Chi-square & P-value \\
\hline $2-3$ & 13 & $7(53.85 \%)$ & $6(46.15 \%)$ & & 0.69 \\
$3-6$ & 14 & $12(85.71 \%)$ & $2(14.29 \%)$ & 0.16 & \\
$6-9$ & 12 & $8(66.67 \%)$ & $4(33.33 \%)$ & & \\
Total & 39 & $27(69.23 \%)$ & $12(30.77 \%)$ & & \\
\hline
\end{tabular}

$\mathrm{N}=$ Total number of animals per breed, $\mathrm{pH}_{45}=\mathrm{pH}$ measured at 45 minute, $\mathrm{pH}_{24}=\mathrm{pH}$ measured at 24 hour (ultimate $\mathrm{pH}$ ), DFD = Dark, Firm and Dry.

Table 4. Quality characteristics of normal and DFD beef (LSM \pm SE).

\begin{tabular}{cccc}
\hline Parameter & Normal meat $(\mathrm{n}=27)$ & $\begin{array}{c}\text { DFD meat } \\
(\mathrm{n}=12)\end{array}$ & P-value \\
\hline $\mathrm{pH}_{45} \mathrm{~min}$ & $6.35 \pm 0.07$ & $6.25 \pm 0.11$ & 0.4606 \\
$\mathrm{pH}_{24} \mathrm{hr}$ & $5.54 \pm 0.07^{\mathrm{b}}$ & $6.16 \pm 0.04^{\mathrm{a}}$ & $<0.0001$ \\
$\mathrm{Temp}_{45} \mathrm{~min}$ & $24.82 \pm 0.21$ & $24.99 \pm 0.31$ & 0.6517 \\
Temp $_{24} \mathrm{hr}$ & $18.43 \pm 0.17$ & $18.47 \pm 0.25$ & 0.0002 \\
$\mathrm{~L}^{*}$ & $34.29 \pm 0.59^{\mathrm{a}}$ & $31.53 \pm 0.83^{\mathrm{b}}$ & 0.8329 \\
$\mathrm{a}^{*}$ & $12.66 \pm 0.30$ & $12.78 \pm 0.23$ & 0.8111 \\
$\mathrm{~b}^{*}$ & $11.14 \pm 0.29$ & $11.01 \pm 0.43$ & 0.29 \\
\hline
\end{tabular}

${ }^{a, b}$ Means in the same row with different letters are significant different $(\mathrm{P}<0.05)$. DFD $=$ Dark firm dry, $n$ $=$ Total number of observation, $\mathrm{pH}_{45} \mathrm{~min}=\mathrm{pH}$ measured at 45 minute (initial $\mathrm{pH}$ ), $\mathrm{pH} 24 \mathrm{hr}=\mathrm{pH}$ measured at 24 hour (ultimate $\mathrm{pH}), \mathrm{L}^{*}=$ Lightness, $\mathrm{a}^{*}=$ Redness, $\mathrm{b}^{*}=$ Yellownes.

mortem and meat become dark in colour [26]. Similarly, relatively lower $L^{*}$ value of DFD meat indicated that the meat was dark in colour which might be associated with stress condition of the cattle before slaughter. Similar to the present study [27] reported lower $\mathrm{L}^{\star}$ value for DFD meat compared to the normal one.

\subsection{Level of Bruised and Non-Bruised Carcass}

The level of bruising and non bruising carcass in slaughtered beef cattle is shown in Figure 2. From total of 39 cattle slaughtered, $26(66.7 \%)$ carcasses were bruised and the rest 13 (33.3\%) were not. Of bruised carcasses, $28.3 \%$ had one 
bruise, $12.8 \%$ had two bruise, $17.9 \%$ had three bruise, $5.1 \%$ had four bruise and $2.6 \%$ had greater than four bruise (Figure 3). The 26 bruised carcasses scored a total of 51 bruising cases. Among these, 35\% were slight, 11 were medium and $5 \%$ were heavy. The mean number of bruise per carcass for bruised carcass was $1.96 \pm 0.25$ while bruise score per carcass was $3.58 \pm 0.68$ (Table 5 ). The current mean number of bruise per carcass was less compared to value reported [28] which was 3.75 point. The present finding of level of bruising was high as compared to cattle slaughtered at South African commercial abattoir which was $5.5 \%$ [16]. The level of in the present study was comparable to bruising reported in Uruguay which was $60.0 \%$ [29]. The higher level of bruising in the present study might due to poor road condition, lack of loading rump at the market, poor vehicle design, poorly designed unloading rump and stunning box used at slaughter house.

The level of bruise by anatomical site is presented in Table 6. The most frequent anatomical site bruise was observed at the backside middle part of carcass (49\%), followed by $17.9 \%$ on hip, $14.3 \%$ on rump and loin, $5.4 \%$ on pin, $5.4 \%$ on rib. With respect to position of bruised part of carcass, from a total of 51 bruised

Table 5. Carcass bruising score for bruised carcass.

\begin{tabular}{ccc}
\hline Size & Bruised cases & Bruise score \\
\hline Slight & 35 & $35 \times 1=35$ \\
Medium & 11 & $11 \times 3=33$ \\
Heavy & 5 & $5 \times 5=25$ \\
Total & 51 & 93 \\
Mean bruise score per carcass & & $93 / 26=3.58 \pm 0.68$ \\
Mean number of bruise per carcass & & $51 / 26=1.96 \pm 0.25$
\end{tabular}

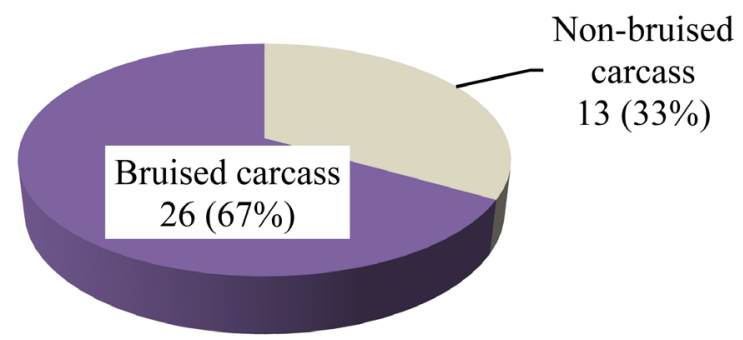

Figure 2. Bruised and non-bruised carcass in slaughtered beef cattle.

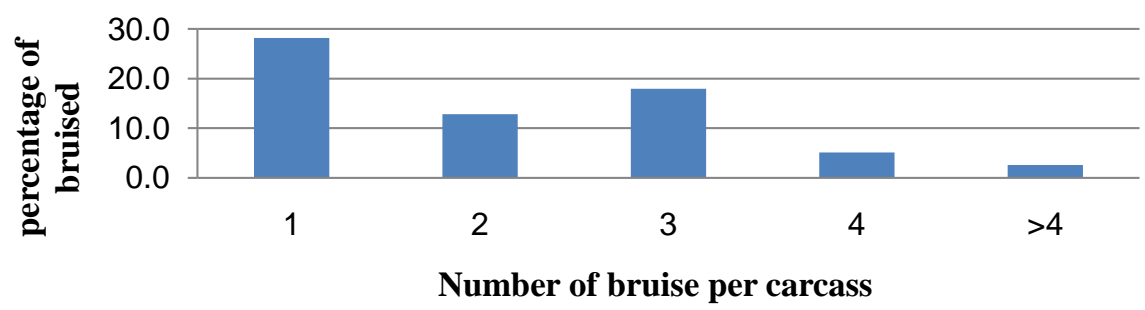

Figure 3. Number of bruise per carcass for bruised carcass ( $n=26$ carcasses). 
Table 6. Anatomical site bruise distribution over carcass.

\begin{tabular}{|c|c|c|c|c|c|c|}
\hline \multirow[b]{2}{*}{ Anatomical site } & \multicolumn{4}{|c|}{ Bruise position } & \multirow[b]{2}{*}{ Chi-square } & \multirow[b]{2}{*}{$\mathrm{P}$-value } \\
\hline & $\begin{array}{c}\text { Left } \\
\mathrm{n}(\%)\end{array}$ & $\begin{array}{l}\text { Right } \\
\text { n (\%) }\end{array}$ & $\begin{array}{c}\text { Middle } \\
\mathrm{n}(\%)\end{array}$ & $\begin{array}{l}\text { Total } \\
\text { n (\%) }\end{array}$ & & \\
\hline Butt & $1(5.6)$ & & & $1(1.8)$ & & \\
\hline Rump and loin & $4(22.2)$ & $4(50)$ & & $8(14.3)$ & & \\
\hline Rib & $1(5.6)$ & $2(25)$ & & $3(5.4)$ & & \\
\hline Forequarter & $1(5.6)$ & & & $1(1.8)$ & 55.15 & 0.001 \\
\hline Back & & & $25(100)$ & $25(49.0)$ & & \\
\hline Hip & $8(44.4)$ & $2(25)$ & & $10(17.9)$ & & \\
\hline Pin & $3(16.7)$ & & & $3(5.4)$ & & \\
\hline Total & $18(100)$ & $8(100)$ & $25(100)$ & $51(100)$ & & \\
\hline
\end{tabular}

cases, the highest 25 (49\%) was found along the middle line of back of carcass, followed by left side of carcass 18 (32.14\%) and the right side of carcass 8 (14\%). Considering the left side carcass, highest bruise was found around the hip (44.4\%) and the lowest around the butt, rib and fore quarter (each 5.6\%). Considering the right side of the carcass, the highest bruise (50\%) was recorded for rump and loin while the lowest was for rib and hip (each 25\%). The highest level of back bruise in current study suggested that the most of slaughtered animals were likely hit by stick during handling (at loading, during driving, weighing), injured from fall down in the stunning box during stunning, collide with facilities such as weighing box and crush. During transporting cattle, appropriate vehicle was not used, instead vehicle (FSR) which were initially meant for transport of goods were used. The drivers of the vehicles drove as if he was carrying goods. The drivers were suddenly holding the brake which had made cattle off balance and the bulls were stacked with the body of the truck or adjacent bulls. The presence of higher level of back bruising in the present study suggested the possibilities for the cause of the bruise at slaughter house. According to [30] most of bruising was occurred at the middle line of carcass which accounts $50.1 \%$ of carcass bruising.

The least bruise which was found at left forequarter and at butt indicated that there was less injury of cattle during closing the doors of weighing scale and stunning box at abattoirs. Rump and loin bruises might be associated with mounting on each other during their stay in the abattoir, injury during loading, collision of bulls with abattoirs facilities (scales, gates, crush) and body of the truck. According to [31] the main factors influencing bruising are stockman-ship, facility and vehicle design, driving style, road conditions, mixing of animals before transport or in lairage, presence of horned animals, and animal temperament. Bruising recorded for the different locations in this investigation was much lower than those reported by [32] who found $72.5 \%$ on Hips, $36 \%$ on rib area and chunk, $31 \%$ on rump, $28 \%$ on the backside, butt and pin area. 
Out 51 bruised cases, $68.62 \%$ were slight, $21.57 \%$ were medium and $9.80 \%$ heavy bruise (Table 7). Likewise, with regarding to colours, $56.86 \%$ were bright red, $37.25 \%$ were dark red and 5.88\% were watery consistency. In current study, most bruises were slight and had a bright red colour which is the indication of fresh bruise. This confirms that most of the bruise was recent and were happen during ante mortem period probably caused during transit, at unloading, or during lairage and at stunning box of the slaughterhouse.

\subsubsection{Shape of Carcass Bruise}

The most frequent bruised shape was linear (33.33\%) followed by irregular (25.49\%), mottled (21.57\%), tram-line (15.68\%) and circular (1.96\%) shape (Figure 4). Bruise shape assist researchers to link the shape of the bruises to their cause [33]. The highest linear shape of bruise in current study indicated that most slaughtered cattle beaten more frequently with driving instruments such as sticks, whip or other rod shaped objects at market, at loading, unloading and in slaughter house. The lowest circular shape of bruising showed that less bruising was found as results of horn as most of slaughtered cattle have short horn and some of them had no horn. Weeks et al. (2002) reported that bruises resulting from cohorts with horns are linked to circular shaped bruises. Tram-line bruises were observed at back middle line, hip, rump and loin resembles the object that inflicted the lesion, as in the case of wooden sticks. Parallel red bruises with a tram-line appearance are likely caused by sticks [34] and mottled bruises can be the result of the use of stone and tip of sticks [35].

\subsubsection{Level of bruising for Boran, Harar and Arsi Breeds}

Level of bruising for Arsi, Boran and Harar cattle are presented in Figure 5. Boran breed had the highest percentage of none bruised carcass (9.4\%) and Harar

Table 7. Size and colour of bruised carcasses.

\begin{tabular}{cccccc}
\hline Bruise size & Frequency & Percent & Bruise colour & Frequency & Percent \\
\hline Slight & 35 & 68.62 & Bright red & 29 & 56.86 \\
Medium & 11 & 21.57 & Dark red & 19 & 37.25 \\
Heavy & 5 & 9.80 & Watery consistency & 3 & 5.88 \\
Total & 51 & 100 & Total & 51 & 100 \\
\hline
\end{tabular}

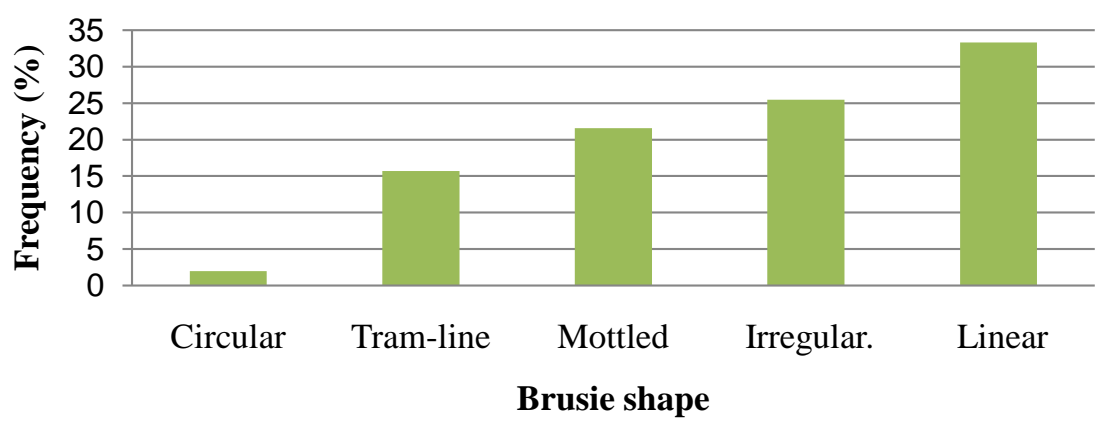

Figure 4. Shape of bruised carcass of slaughtered beef cattle. 


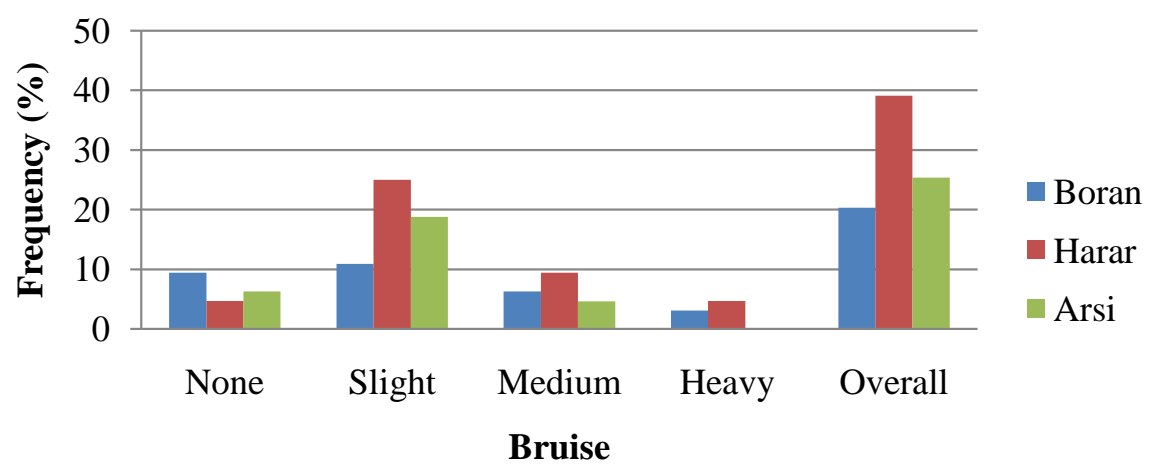

Figure 5. Level Bruising for Arsi, Boran and Harar beef cattle.

breed had the lowest percentage of non-bruised carcass (4.7\%). Harar breed had the highest (25\%) slight bruised carcass while Boran breed had lowest $10.9 \%$ slight bruised. This was due to difference in loading rump facility and handling of cattle. The higher slight bruise score for Harar breed might due to absence of appropriate loading rump during loading cattle so that the cattle fall and collide with the side of truck at the time of loading; cattle mixed with unfamiliar animals that were purchased from market. Mixing unfamiliar animals to each other cause butting, attacking and fighting which increases the risk of bruising in beef cattle [36]. The lowest slight bruise in case of Boran breed might due to well-designed loading rump present at ranch during loading and individual bulls were not new to each other since they were reared together in the same ranch.

Harar breed had the highest (9.4\%) medium bruised carcass and Arsi breed have the lowest $(4.6 \%)$ medium bruised carcass. This might be due to road condition under which animal was transported. Harar breed transported under road condition such as many curves and speed of the vehicle hold break suddenly which possibly made the bulls to collided with the side of the truck during transporting. It was possible that such condition might expose the breed to many multiple bruising per anatomical site which was recorded for the breed.

Boran and Harar breed had the lowest percentage of heavy bruised carcass. No heavy bruise observed in Arsi breed. This might also associated with road condition under which animal transported. Boran and Harar breed transported on relatively more detour road while Arsi breed transported relatively on smooth. The occurrence of bruising not only affected by facility, road condition and mixing with unfamiliar cattle but also by other factors such as inappropriate handling before slaughter, vehicle design and driving style [37]. The difference in severity of bruises between breeds in the present study might also contribute due to difference in temperament of breeds under study. Some differences in the occurrence and severity of bruises associated with breeds suggested by [28]. The overall bruise showed that Harar breed had higher bruise (39.1\%), followed by Arsi breed 25.4\% and Boran breed 20.3\%. This indicated that Harar and Arsi breed purchased from markets had higher overall bruise score than Boran breed that directly transported from ranch to slaughter house due to their exposure to 
more handling, loaded without appropriate loading rump and mixed with unfamiliar animals. Cattle purchased from markets had more bruises than cattle coming directly from the farm [38]. However, the absence of differences in bruise scores between animals transported direct from farm to slaughter house as compared to those have been through market was reported by [5].

\subsubsection{Level of Bruising for Different Age Groups}

The highest percentage of slight bruise (21.9\%) was observed in 3 - 6 years old and the lowest percentage of slight (15.6\%) were observed in 6 - 9 years old (Figure 6). The highest medium bruise (9.4\%) was found in 6 - 9 years old and the 3 - 6 years old had the lowest medium (1.6\%) bruise. The highest heavy bruise was found in $3-6$ and 6 - 9 years old respectively and the lowest heavy bruise was found in 2 - 3 years old. The overall bruising score indicated those at age group of 3-6 years and 6 - 9 had the higher bruise score $(29.70 \%$ and $28.10 \%$ respectively) than $2-3$ years $(21.90 \%)$ age group. This indicates that the old animals are more prone to bruising than the young animals. The higher bruise score might be due to difference in fat cover and fat thickness. The fat thickness of 3 - 6 and 6 - 9 years almost similar $(1.20 \pm 0.36$ inch and $1.21 \pm 0.39$ inch respectively) while 2 - 3 age group had less fat thickness $(0.54+0.33$ inch) as shown in Table 8. These shown old animals had more fat cover and had more fat thickness than younger animals. Old age groups that had more fat and heavy weight mostly injured specially during fall in the stunning box. It has been suggested that fat cover, skin and hide thickness could affect the susceptibility to bruising from impacts with a similar force [30]. The current finding is in agreement with who reported that the heavy animals were more bruised than young animals [39]. However contradict with result found by [40] who described that bruising is higher in young animals than older.

\subsubsection{Age of Bruise}

The colours of slight, medium and heavy bruised carcass were described in Figure 7. Slight bruise had $68.57 \%$ and $31.43 \%$ of bright ( 0 - 10 hours) and dark red colours (11 - 24 hours), respectively, while medium bruise consists of $63.64 \%$ bright red and $36.36 \%$ dark red colours. Heavy bruise had $40 \%, 40 \%$ and $20 \%$ bright red, dark red and water consistency colours (25 - 38 hours) respectively. In all bruise scores (slight, medium \& heavy), bruise colous (bright red, dark red \& water consistency) indicated that bruise was recent and happened during

Table 8. Fat thickness for different age categories.

\begin{tabular}{cc}
\hline Age group (years) & Fat thickness (inch) \\
\hline $2-3$ & $0.54 \pm 0.33^{\mathrm{b}}$ \\
$3-6$ & $1.20 \pm 0.36^{\mathrm{a}}$ \\
$6-9$ & $1.21 \pm 0.39^{\mathrm{a}}$ \\
P-value & 0.03
\end{tabular}

Means within different letters in the same column are significantly different $(\mathrm{p}<0.05)$. 


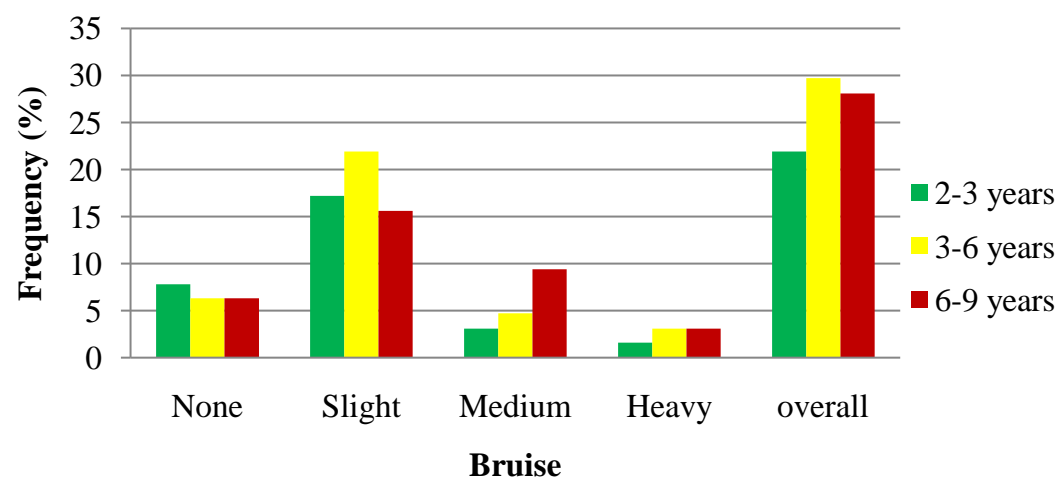

Figure 6. Level of bruise for different age groups of beef cattle slaughtered at abattoirs.

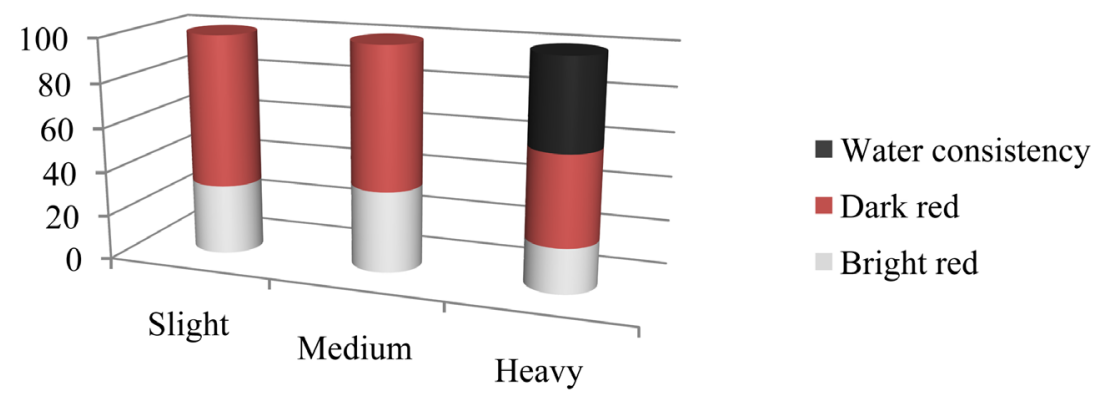

Figure 7. Bruise age. Slight $=0-10$ hours old (bright red), $11-24$ hour (Dark red), Medium $=0-10$ hours old (bright red) and $11-24$ hours (Dark-red), Heavy $=0-10$ hours old (bright red), 11 - 24 hour (Dark red) and 25 - 38 hours (Watery consistency).

ante mortem period probably caused during loading, transit and at the abattoir (during unloading, lairage and at stunning box). Estimating the age of a bruise by colour can provide for the identification of the place and time of livestock damage. Hence good handling, transportation and abattoir management practice should be considered to reduce the level of bruise.

\section{Conclusion}

From current study, it was concluded that level of dark firm dry does not significantly influence by breed and age groups, however, level of bruise varies with breed and age categories. The quality of meat is greatly influenced by stress before slaughter which had a significant influence on lightness and ultimate $\mathrm{pH}$. The occurrences of bruising vary with anatomical site, size, shape and colors. High level of bruising and DFD in present suggested the presence of poor handling during loading, transportation, unloading, at lairrage and during slaughter at abattoir. To reduce the incidence of DFD and bruising, proper handling of cattle from farm to abattoir should be practiced. To determine whether the occurrences of bruising and DFD are due to genetic or environmental condition further evaluation of three breeds under similar management was recommended.

\section{Acknowledgements}

I gratefully acknowledge to Ethiopian Meat and Dairy Industry Development 
Institute (EMDIDI) and American people through the United States Agency for International Development (USAID) and its Feed, the Future Innovation Lab for Livestock Systems managed by the University of Florida for providing financial support to conduct this research.

\section{Conflicts of Interest}

There is no conflict of interest regarding this manuscript.

\section{References}

[1] Central Statistics Survey Agricultural Sample Survey (2016/2017) Report on Livestock and Livestock Characteristics. Statistical Bulletin, Volume II: 585, Addis Ababa, Ethiopia.

[2] Ministry of Agriculture (1996) Fattening Extension Manual. MOA, Animal and Fishery Resource Main Department, FLDP (Fourth Livestock Development Project), Addis Ababa, Ethiopia.

[3] Mummed, Y.Y. (2015) Beef Carcass Quality, Yield and Cause of Condemnation in Ethiopia. Ph.D. Dissertation, Pretoria University, South Africa, Pretoria.

[4] Adzitey, F. (2011) Effect of Pre-Slaughter Animal Handling on Carcass and Meat Quality: Mini Review. International Food Research Journal, 18, 484-490.

[5] Jarvis, A.M., Selkirk, L.D. and Cockram, M.S. (1995) The Influence of Source, Sex Class and Pre-Slaughter Handling on the Bruising of Cattle at Two Slaughterhouses. Livestock Production Science, 43, 215-224. https://doi.org/10.1016/0301-6226(95)00055-P

[6] Gupta, S., Earley, B. and Crowe, M.A. (2007) Effect of 12 Hour Road Transportation on Physiological, Immunological and Hematological Parameters in Bulbs Housed at Different Space Allowances. The Veterinary Journal, 173, 605. https://doi.org/10.1016/j.tvjl.2006.03.002

[7] Adzitey, F. and Nurul, H. (2011) Pale Soft Exudative (PSE) and Dark Firm Dry (DFD) Meats: Causes and Measures to Reduce These Incidences. International Food Research Journal, 18, 11-20.

[8] Scanga, J.A., Belk, K.E., Tatum, J.D., Grandin, T. and Smith, G.C. (2003) Factors Contributing to the Incidence of Dark Cutting Beef. Journal of Animal Science, 76, 2040-204. https://doi.org/10.2527/1998.7682040x

[9] Torell, R., Bruce, B. and Kvasnicka, B. (2003) Method of Determine Age of Cattle. Cattle Producer Library-CL712.

[10] Anderson, B. and Horder, J.C. (1979) The Australian Carcasses Bruise Scoring System. Queensland Agricultural Journal, 105, 281-287.

[11] Gracey, J.F. and Collins, D.S. (1992) Meat Hygiene. Bailliere Tindall, London.

[12] Viljoen, H.F., DeKock, H.L. and Webb, E.C. (2002) Consumer Acceptability of Dark, Firm and Dry and Normal pH Beef Steaks. Meat Science, 61, 181-185. https://doi.org/10.1016/S0309-1740(01)00183-8

[13] Page, J.K., Wulf, D.M. and Schwotzer, T.R. (2001) A Survey of Beef Muscle Color \& pH. Journal of Animal Science, 79, 678-687. https://doi.org/10.2527/2001.793678x

[14] Commission International De I’ Eclairage Colorimetry (1976) Vienna, Switzerland, CIE.

[15] Chulayo, A.Y. and Muchenje, V. (2013) The Effects of Pre-Slaughter Stress and 
Season on the Activity of Plasma Creatine Kinase and Mutton Quality from Different Sheep Breeds Slaughtered at a Smallholder Abattoir. Asian-Australasian Journal of Animal Science, 26, 1762-1772. https://doi.org/10.5713/ajas.2013.13141

[16] Viljoen, H.F. (2000) Meat Quality of Dark-Cutting Cattle. University of Pretoria, South Africa.

[17] Rosa, A., Poleti, M.D., Eler, J.P. and Balieiro, J.C. (2016) Conference Paper in Meat Science.

[18] Savell, J.W., Hale, D.S., Graffin, D.B., Kerth, C.R. and Belke, K.E. (2011) National Beef Quality Audit-2011 in Plant Survey Phase. Funded in Part the Beef Check off, USA.

[19] Van Donkersgoed, J.J., Bygrove, G. and Gillis, K. (2017) Canadian Beef Quality Audit. The Canadian Veterinary Journal, 43, 121-126.

[20] Miller, G.E., Chen, E. and Zhou, E.S. (2007) If It Goes Up, Must It Come Down? Chronic Stress and the Hypothalamic-Pituitary-Adrenocortical Axis in Humans Psychological Bulletin, 133, 25-45. https://doi.org/10.1037/0033-2909.133.1.25

[21] Mummed, Y.Y. and Webb, E.C. (2014) Ethiopian Beef Carcass Characteristics. African Journal of Agricultural Research, 9, 3766-3775.

[22] Mummed, Y.Y. and Webb, E.C. (2015) Carcass Quality Audit-A Strategy to Improve Beef Sector in Ethiopia. African Journal of Agricultural Research, 10, 2731-2737. https://doi.org/10.5897/AJAR2015.9524

[23] Asfaw, N. and Jabbar, M. (2007) Commercial Offtake of Cattle under Smallholder Mixed Crop-Livestock Production System in Ethiopia, Its Determinants and Implications for Improving Live Animal Supply for Export Abattoirs. ILRI, Addis Ababa, Ethiopia.

[24] Onenc, A. (2004) Dark Cutting Incidence in Holstein Friesian, Brown Swiss and Eastern Anatolian Red Cattle Slaughtered Under Turkish Commercial Slaughter Conditions. Pakistan Journal of Biological Science, 7, 96-99. https://doi.org/10.3923/pjbs.2004.96.99

[25] Marencic, D., Ivankovic, A., Kozacinskic, L., Popovic, M. and Cvrtila, Z. (2018) The Effect of Sex and Age at Slaughter on the Physicochemical Properties of Baby-Beef Meat. Veterinarski Arhiv, 88, 101-110. https://doi.org/10.24099/vet.arhiv.160720

[26] Chulayo, A.Y., Tada, O. and Muchenje, V. (2012) Research on Pre-Slaughter Stress and Meat Quality: A Review of Challenges Faced under Practical Conditions. Applied Animal Husbandry \& Rural Development, 5, 1-6.

[27] Webb, E., Simela, L. and Frylinck, L. (2004) Effect of Sex, Age, and Pre-Slaughter Conditioning on $\mathrm{pH}$, Temperature, Tenderness and Colour of Indigenous South African Goats. South African Journal of Animal Science, 34, 208-201.

[28] Huertas, S.M., Kempener, A.M. and Eerdenburg, M.V. (2018) Relationship between Methods of Loading and Unloading, Carcass Bruising, and Animal Welfare in the Transportation of Extensively Reared Beef Cattle. Animals, 7, 119-127. https://doi.org/10.3390/ani8070119

[29] Piaggio, J., Gil, A., Eerdenburg, F.V. and Huertas, A.M. (2015) Prevalence of Carcass Bruises as an Indicator of Welfare in Beef Cattle and the Relation to the Economic Impact. Veterinary Medicine and Science, 1, 9-15.

https://doi.org/10.1002/vms3.2

[30] Jeffrey, W.S. (2012) National Beef Quality Audit-2011: Harvest Floor Assessment.

[31] Grandin, T. (2007) Handling and Welfare of Livestock in Slaughter Plants. 3rd Edition, CABI, Cambridge, MA. 
[32] Hoffman, L. and Luhl, J. (2012) Causes of Cattle Bruising during Handling and Transport in Namibia. Meat Science, 92, 115-124. https://doi.org/10.1016/j.meatsci.2012.04.021

[33] Grandin, T. (2019) Livestock Handling and Transport. CABI Publishing, Wallingford, Oxon, UK.

[34] Weeks, C.A., McNally, P.W. and Warriss, P.D. (2002) Influence of the Design of Facilities at Auction Markets and Animal Handling Procedures on Bruising in Cattle. Veterinary Record, 150, 743-748. https://doi.org/10.1136/vr.150.24.743

[35] Gallo, C., Caro, M. and Villarroel, C.C. (1999) Characteristics of Cattle Slaughtered within the $\mathrm{X}^{\text {th }}$ Region (Chile) According to the Terms Stated by the Official Chilean Standards for Classification and Carcass Grading. Archivos de Medicina Veterinaria, 31, 81-88. https://doi.org/10.4067/S0301-732X1999000100008

[36] Warriss, P.D., Brown, S.N., Adams, S.J. and Lowe, D.B. (1990) Variation in Haem Pigment Concentration and Colour in Meat from British Pigs. Meat Science, 28, 321-329. https://doi.org/10.1016/0309-1740(90)90046-9

[37] Strappini, A.C., Frankena, K., Metz, J.H.M., Gallo, C.B. and Kemp, B. (2010) Prevalence and Risk Factors for Bruises in Chilean Bovine Carcasses. Meat Science, 86, 859-864. https://doi.org/10.1016/j.meatsci.2010.07.010

[38] Costa, L.N., Lofigo, D.P., Tassone, F. and Russo, V. (2006) The Relation between Carcass Bruising in Bulls and Behavior Observed during Pre-Slaughter Phase. Veterinary Research Communication, 30, 379-381. https://doi.org/10.1007/s11259-006-0086-9

[39] Wythes, J.R. and Shorthose, W.R. (1991) Chronological Age and Dentition Effects on Carcass and Meat Quality of Cattle in Northern Australia. Australian Journal of Experimental Agriculture, 31, 145-152. https://doi.org/10.1071/EA9910145

[40] Strappini, A.C., Metz, J.H., Gallo, C.B. and Kemp, C.B. (2009) Origin and Assessment of Bruises in Beef Cattle at Slaughter. Journal of Animal Science, 3, 728-736. https://doi.org/10.1017/S1751731109004091 